\title{
The effect of nonreinforced stimulus exposure on the strength of a conditioned taste aversion as a function of retention interval: Do latent inhibition and extinction involve a shared process?
}

\author{
PHILIPP J. KRAEMER \\ University of Kentucky, Lexington, Kentucky \\ and \\ NORMAN E. SPEAR
}

Center for Developmental Psychobiology, State University of New York, Binghamton, New York

\begin{abstract}
Two experiments examined the effects of nonreinforced flavor exposure on the strength of a conditioned taste aversion. Rats were conditioned by pairing maple flavor with $\mathrm{LiCl}$. Prior to or subsequent to this pairing, some animals received nonreinforced exposure to either maple or saccharin. In separate subjects, preference for maple was tested 1 or 21 days after the last training episode. In the first experiment, the nonreinforced stimulus exposure occurred before conditioning (latent inhibition, or LI, procedure); in the second experiment, the nonreinforced exposure occurred after conditioning (extinction, or EXT, training). In both experiments, nonreinforced exposure to maple or saccharin reduced the magnitude of a conditioned maple aversion when testing occurred soon after conditioning. When testing was delayed, however, the attenuation due to nonreinforced saccharin exposure dissipated, both with the LI procedure and with EXT. In contrast, the nonreinforced exposure to maple was found to attenuate conditioned reactions at both short and long retention intervals. The release from generalized LI and spontaneous recovery following generalized EXT training are discussed in terms of retrieval processing. The possibility that the same mechanism may underlie LI and EXT is considered.
\end{abstract}

There is a striking procedural similarity between latent inhibition (LI) and extinction (EXT); both involve exposing the subject to contingent CS-US pairings as well as to presentations of the CS alone. The obvious difference between them is the order in which the two events are presented. The CS-alone episode precedes the CS-US pairing with LI, whereas the two events occur in the reverse order with EXT. Despite this procedural symmetry, the two phenomena have not been considered to be theoretically comparable. Explanations of EXT have typically emphasized representational content, either in the form of changes in existing CS-US associations (Rescorla \& Wagner, 1972) or as the formation of competing associations (Bouton, 1991; Pavlov, 1927; Pearce \& Hall, 1980). In contrast, $L I$ has been explained as a disruption in the encoding process itself. The accepted view has been that prior experience with a stimulus interferes with an

\footnotetext{
The present research was supported by grants from the National Institute of Mental Health (Grant 1R03 MH 42992 to P. J. Kraemer and Grant 1R01 MH 35219 to N. E. Spear). Correspondence should be addressed to Philipp J. Kraemer, Department of Psychology, University of Kentucky, Lexington, KY 40506-0044.
}

animal's ability to learn about a CS during a subsequent conditioning episode (Lubow, 1973, 1989; Mackintosh, 1983). Although several different mechanisms have been proposed to account for the putative encoding deficit, the alternatives agree that the CS-US association is less well established with stimuli that are familiar than with those that are novel (Baker \& Mercier, 1982; Best \& Barker, 1977; Best \& Gemberling, 1977; Kalat, 1977; Kalat \& Rozin, 1973; Lubow, Weiner, \& Schnur, 1981; Mackintosh, 1975; Pearce \& Hall, 1980; Wagner, 1978, 1981).

Recent investigations have begun to challenge the encoding-failure view of $L I$. In two vastly different situations, evidence has indicated that the representation of CS-US relations is not necessarily disrupted by stimulus preexposure. Kasprow, Catterson, Schachtman, and Miller (1984), using conditioned lick suppression, found that preexposure to a white-noise CS reduced the level of expressed fear following CS-footshock pairings. More important, they also found that postacquisition shock-alone presentations, administered in a separate context from that used for conditioning, were sufficient to significantly reduce the magnitude of $L I$. An effect of this nature indicates that CS preexposure did not prevent the formation of the CS-US representation. 
A similar conclusion was reached by Kraemer and Roberts (1984) in a set of experiments involving conditioned taste aversions. Rats that were preexposed to a flavor expressed weaker conditioned aversions than did nonpreexposed subjects, but this effect only appeared when testing occurred soon after conditioning. When testing was delayed by 21 days, there was a release from $\mathrm{LI}$; preexposed subjects displayed aversions equal in strength to those expressed by nonpreexposed subjects. This effect again implies that stimulus preexposure does not necessarily diminish an animal's ability to represent the conditioning episode.

Taken together, the two sets of findings present a paradox for the encoding-failure view of LI. If preexposure disrupts encoding, then how can animals under some conditions (i.e., with postacquisition exposure to the US or with delayed testing) behave as if they had learned as much or as well as nonpreexposed animals?

An alternative to the encoding-failure view is the possibility that stimulus preexposure disrupts retrieval, rather than storage, of the conditioning episode (Miller, Kasprow, \& Schachtman, 1986; Spear, 1981). Kraemer and Roberts (1984) offered a retrieval processing analysis of LI intended to account for the release-from-LI effect. It assumes that memories for preexposure and conditioning are mutually disruptive during the retrieval episode. When the test occurs soon after conditioning, appropriate retrieval cues, such as the test flavor, can activate the preexposure memory, the conditioning memory, or both, due to the shared content of these memories. The resultant retrieval competition then translates into a decreased tendency for the conditioning memory to be expressed during testing, which is indexed behaviorally as a weaker aversion to the test flavor than that found in nonpreexposed subjects. It is further assumed that the retrievability of the preexposure memory declines over the course of an extended retention interval. The consequence of this change is a reduction or elimination of retrieval competition, which leads to the appearance of a strong conditioned response.

It is interesting to consider that a very similar analysis can be generated for EXT. Theories such as that of Pearce and Hall (1980) have suggested that nonreinforced exposure to a CS after conditioning results in representation of a CS-no-US relationship. A retrieval processing account of EXT adds the assumption that retrieval competition between the conflicting memories is responsible for the reduction in the expressed strength of the conditioned response. When testing occurs soon after EXT, there is a decreased likelihood that the conditioning memory will be retrieved, which is similar to the analysis presented above for LI. Bouton (1991) has recently presented a forceful argument, supported by an impressive set of findings, in favor of a retrieval processing account of EXT. By adding one further assumption, that memory for EXT gradually becomes less retrievable over time, the phenomenon of spontaneous recovery can be viewed as analogous to release from $\mathrm{LI}$. Over a long reten- tion interval, the probability that the conditioning memory will be retrieved and expressed increases, as seems to occur with LI.

The important implication of this proposal is that EXT and LI may depend on a common process (Bouton, 1991), which is contrary to prevailing opinion and inconsistent with most formal models of conditioning (Grossberg, 1982; Holyoak, Koh, \& Nisbett, 1989; Mackintosh, 1975; Pavlov, 1927; Pearce, 1987; Pearce \& Hall, 1980; Rescorla \& Wagner, 1972; Wagner, 1981). One way to establish that a common process is shared by two phenomena, such as the effects of prior or subsequent nonreinforcement, is to show that they are similarly influenced by the same independent variables (see Spear \& Spitzner, 1967, for a similar approach involving instrumental learning). Although there is no direct evidence, there is some indication of a functional similarity between LI and EXT. For example, there is clear evidence that both $\mathrm{LI}$ and EXT are modulated by contextual cues. When conditioning occurs in one distinct context and nonreinforced exposure in another, conditioned responding is much stronger than when both episodes occur in the same context, both for EXT (Bouton, 1991) and for LI (Hall \& Channell, 1986; Hall \& Minor, 1984).

The present study examined this issue more directly. The release-from-LI effect has been shown to be related to the nature of the stimuli used for preexposure and conditioning. Although release from LI has been obtained with primary preexposure (i.e., exposure to the CS itself; see Kraemer, Randall, \& Carbary, 1991; Kraemer \& Roberts, 1984; Strohen, Bakner, Nordeen, \& Riccio, 1990), the effect has been most pronounced and reliable when preexposure is to a stimulus other than the CS (i.e., generalized preexposure; see Kraemer, Hoffmann, \& Spear, 1988; Kraemer \& Ossenkopp, 1986; Kraemer \& Roberts, 1984). We compared the effect of stimulus similarity in the LI and EXT procedures. If the releasefrom-LI effect and spontaneous recovery reflect a common process, then the nature of the nonreinforced flavor experience should influence both phenomena in the same way. Specifically, delayed testing should exert a differential effect on generalized and primary EXT, parallel to what has been found with generalized and primary LI. Postacquisition exposure to either the flavor CS or some similar flavor should attenuate conditioned aversions to the CS when testing occurs soon after EXT. Following a long retention interval, attenuated aversions should be more likely with primary EXT; that is, spontaneous recovery should occur more readily with generalized EXT than with primary EXT.

Independent of the pertinent theoretical issues, this study provides an important empirical contribution, given that no previous studies have assessed the effects of either primary or generalized EXT after extended retention intervals with conditioned taste aversions. This information offers a further means of comparing the CTA procedure with other forms of learning (Domjan, 1983). Equally important, this study provides another replication of the basic 
release-from-LI effect. Given the provocative implications of this effect, demonstration of its reliability seems in order.

Although the stimulus experiences provided with $\mathrm{LI}$ and EXT are comparable, we chose to conduct this study as two related experiments rather than within a single complex design. The rationale was that there are minor yet important methodological differences between the two procedures that confound direct comparisons across groups. This is especially important for subjects given LI or EXT training and tested after a short retention interval. For example, it is reasonable to expect that overall consumption during testing at the short delay interval will differ for animals given EXT and LI; subjects given the LI procedure are expected to consume high amounts of the CS on the conditioning day, the day before they are tested, whereas subjects given EXT are expected to drink less on the day before they are tested (the last EXT episode), given that some conditioned aversion would be expected in these subjects. The relative recency of toxicosis also differs for the two procedures. Animals are injected the day before testing with the LI procedure, but, for those given EXT training, the consequences of $\mathrm{LiCl}$ injection are separated from the test day by the intervening EXT experience. Our strategy, therefore, was to adopt the more conservative approach by examining the effects of flavor similarity and retention interval with the two procedures in separate experiments.

\section{METHOD}

\section{Subjects and Apparatus}

The subjects were adult male Sprague-Dawley-derived rats. The 48 subjects in Experiment 1A (LI) were taken from the rat colony at Purdue University; the 64 subjects in Experiment $1 B$ were taken from the colony at SUNY-Binghamton. Animal housing and maintenance procedures were comparable at the two institutions. The subjects were individually housed in hanging stainless steel cages located in climate-controlled vivaria, which also served as the test rooms. These rooms operated on a 16:8-h light:dark cycle; all testing occurred during the 16-h light phase. Each rat was placed on a 23.5-h water-deprivation schedule 7 days prior to the start of each experiment. Food was always available. Liquids were dispensed at room temperature through graduated glass bottles, fitted with stainless steel spouts. Bottles were attached to the front of each subject's cage during liquid presentations, and consumption was recorded to the nearest milliliter. Test flavors consisted of $0.58 \%(v / v)$ mapleflavored water and $0.15 \%(w / v)$ sodium saccharin.

\section{Procedure}

Experiment 1A. On Days 1 and 2 of Experiment 1A, the subjects received 30-min access to either tap water (Group $\mathbf{M}+$ ), maple (Group $\mathbf{M}-\mathbf{M}+$ ), or saccharin (Group $\mathbf{S}-\mathbf{M}+$ ). On Day 3, all subjects were given 30 -min access to maple, followed immediately by a $1 \%$ bodyweight i.p. injection of $0.3-\mathrm{M} \mathrm{LiCl}$. Half of the subjects in each of the three groups were tested the next day; the remaining subjects were tested after a 21-day retention interval. The latter subjects were allowed free access to water from the day after conditioning until 11 days before testing, at which time they were again placed on 23.5 -h water deprivation. Testing involved 30-min access to two bottles; one contained tap water and the other contained maple. The left/right position of the two bottles was balanced across subjects in each of the six groups.
Experiment 1B. On Day 1 of Experiment 1B, all subjects received 30-min access to maple, either followed immediately (Groups $\mathbf{M}+, \mathbf{M}+\mathbf{M}-$, and $\mathbf{S}-\mathbf{M}+$ ) or, after a 6-h delay (Group $\mathbf{M}-$ ), by a $1 \%$ bodyweight i.p. injection of $0.3-\mathrm{M} \mathrm{LiCl}$. On Days 2 and 3 , each subject received 30 -min access to either tap water (Groups $M+$ and $\mathbf{M - \text { ) }}$, maple (Group $\mathbf{M}+\mathbf{M}-$ ), or saccharin (Group $\mathbf{M}+\mathbf{S}-$ ). Half of the animals in each group were then tested the next day, and the others were tested after a 21-day retention interval. The remainder of the procedure followed that described for Experiment $1 \mathrm{~A}$.

\section{RESULTS}

\section{Experiment 1A}

All statistical analyses were evaluated at $p=.05$, and Newman-Keuls tests were used to evaluate comparisons between group means. Mean consumption for each group tested in Experiment 1A during each of the two preexposure sessions and the conditioning episode is presented in Table 1.

Consumption during the first preexposure period differed significantly across the three groups $[F(2,45)=$ 29.9]. The amount of maple consumed by Group $M-M+$ was not significantly different from the amount of water consumed by Group $\mathbf{M}+$; both groups drank more than the amount of saccharin consumed by Group $S-M+$. No significant differences in consumption across the three groups appeared during the second preexposure period, but differences between groups did appear in the amount of maple consumed during the conditioning episode $[F(2,45)=9.97]$. Group $S-M+$ drank significantly less than did either Group $\mathbf{M}+$ or Group $\mathbf{M}-\mathbf{M}+$; the latter two groups drank nearly equal amounts. These results indicate that there was no evidence of flavor neophobia for subjects given maple; these subjects consumed as much liquid during the first preexposure period as did subjects given water (Group $\mathbf{M}+$ ). The lower consumption of saccharin during the first preexposure period, relative to maple and water, indicates either a neophobic reaction or a lower preference for saccharin. The former possibility is more likely, given the absence of significant consumption differences across the three groups during the second preexposure period.

Percent maple preferences were calculated for each subject according to the following formula: (amount of maple consumed/amount maple + amount water consumed) $\times 100$. The mean percent maple preference for each group appears in Panel A of Figure 1.

It can be seen that, at the 1-day retention interval, the two preexposed groups displayed higher preferences than

Table 1

Mean Consumption During Preexposure and Conditioning in Experiment 1A

\begin{tabular}{lccc}
\hline Group & Conditioning & Preexposure 1 & Preexposure 2 \\
\hline M+ & 20.4 & 19.8 & 21.7 \\
S-M+ & 15.0 & 12.2 & 20.0 \\
M-M+ & 22.4 & 19.1 & 21.0 \\
\hline
\end{tabular}

Note-Consumption is expressed in milliliters. 
did the nonpreexposed group. Differences in preference levels across the three groups were significant $[F(2,21)$ $=11.0, p<.001]$, and it was determined that the preferences in Groups $\mathbf{S}-\mathbf{M}+$ and $\mathbf{M}-\mathbf{M}+$ did not differ significantly and were higher than those displayed by Group $\mathrm{M}+$. Preferences also differed significantly at the 21-day retention interval $[F(2,21)=9.4, p<.01]$. Preferences in Groups $\mathbf{M}+$ and $S-M+$ did not differ significantly and were significantly lower than those of Group $\mathbf{M}-\mathbf{M}+$. These results replicate the release-fromLI effect reported previously and again show that the effect is influenced by stimulus characteristics; although a release from LI was obtained with generalized preexposure, it did not appear with primary preexposure (Kraemer \& Ossenkopp, 1986; Kraemer \& Roberts, 1984).

\section{Experiment 1B}

Mean consumption during the conditioning episode and each of the two extinction sessions appears in Table 2.

Amount of maple consumed during conditioning did not differ among the four groups, but significant differences
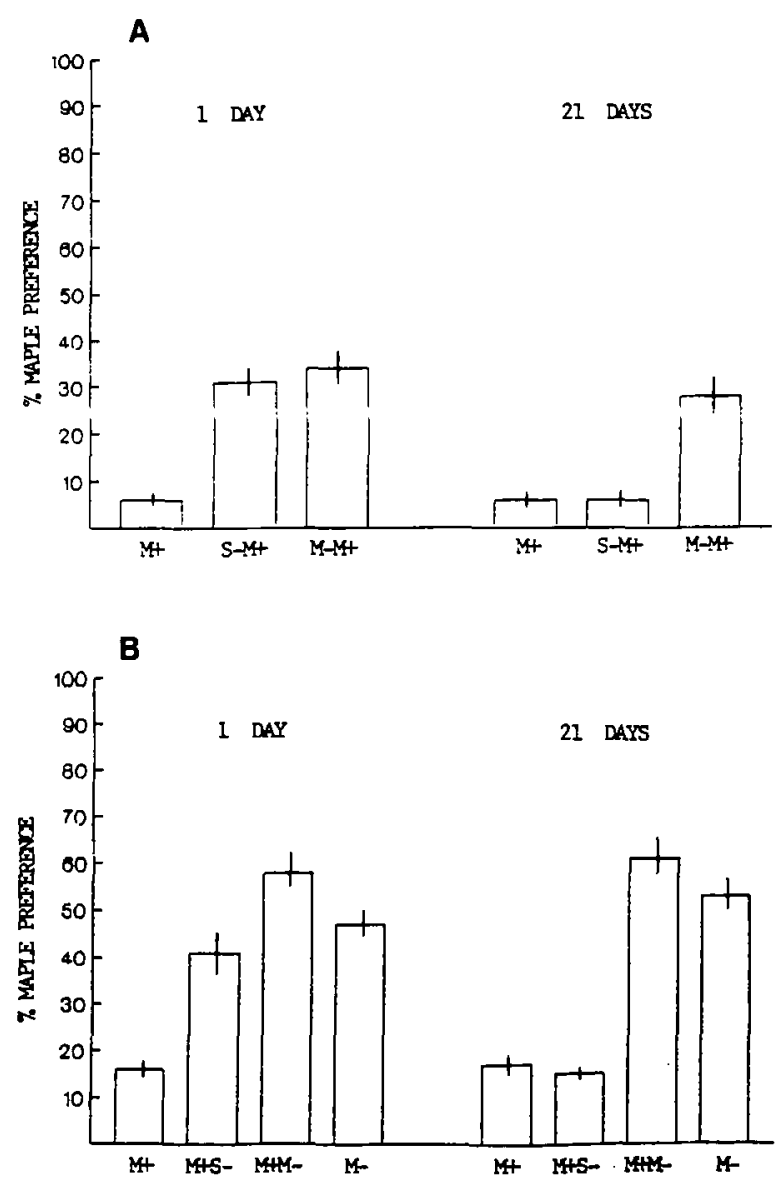

Figure 1. Mean percent maple preference for each group tested in Experiment $1 \mathrm{~A}$ (Panel $\mathrm{A}$ ) and Experiment $1 B$ (Panel B). $M=$ maple, $\mathrm{S}=$ saccharin, + refers to presentation of $\mathrm{LiCl}$ immediately after favor exposure, and - refers to the absence of an immediate injection of $\mathrm{LiCl}$ following flavor exposure.
Table 2

Mean Consumption During Conditioning and Extinction in Experiment $1 B$

\begin{tabular}{lccc}
\hline Group & Conditioning & Extinction 1 & Extinction 2 \\
\hline $\mathrm{M}+$ & 19.6 & 13.8 & 21.7 \\
$\mathrm{M}+\mathrm{S}-$ & 18.4 & 9.0 & 19.8 \\
$\mathrm{M}+\mathrm{M}-$ & 20.8 & 10.4 & 17.1 \\
$\mathrm{M}-$ & 18.0 & 18.0 & 18.0 \\
\hline
\end{tabular}

Note-Consumption is expressed in milliliters.

did emerge during the first extinction session $[F(3,60)=$ 19.05]. Group $M$ - drank significantly more water than the amount of liquids consumed by each of the other three groups. Group $\mathbf{M}+$ drank significantly more water than Group $\mathbf{M}+\mathbf{S}-$ drank saccharin and Group $\mathbf{M}+\mathbf{M}-$ drank maple; consumption by the latter two groups did not differ significantly. Levels of liquid consumption across the four groups did not differ during the second extinction session. These results establish that pairing maple with $\mathrm{LiCl}$ produced a conditioned aversion to both maple and saccharin and that a single extinction session was sufficient to eliminate both primary and generalized aversions.

Mean percent maple preferences for the eight groups appear in Panel B of Figure 1. It can be seen that maple preferences differed significantly among the four groups tested after the 1-day retention interval $[F(3,28)=4.3]$. Individual group comparisons revealed that preferences in Groups $\mathbf{M}+\mathbf{M}-, \mathbf{M}+\mathbf{S}-$, and $\mathbf{M}-$ were equal, and they were higher than those of Group $M+$. Preferences also differed among the four groups at the 21-day retention interval $[F(3,28)=8.33]$, but the pattern of differences was unlike that found at the 1-day retention interval. Preferences in Groups $\mathbf{M}-$ and $\mathbf{M}+\mathbf{M}-$ were not different and were significantly higher than those found in Groups $\mathbf{S}-\mathbf{M}+$ and $\mathbf{M}+$; preferences in the latter two groups did not differ significantly. These results indicate that both generalized and primary EXT attenuated aversions to maple when testing occurred after a 1-day retention interval, but not when testing was delayed by 21 days; then, only primary EXT continued to have an attenuating effect. Stated differently, spontaneous recovery was evident after generalized EXT, but not after primary EXT.

\section{DISCUSSION}

In separate experiments, one involving an LI procedure and the other an EXT procedure, the effect of nonreinforced flavor exposure was found to be influenced by retention interval. Exposure to saccharin reduced the magnitude of a conditioned maple aversion when testing occurred after a 1-day retention interval, but not when testing was delayed by 21 days; exposure to the maple CS itself, however, attenuated aversion strength at both retention intervals. This pattern of results was the same regardless of whether the nonreinforced exposure occurred before (LI) or after conditioning (EXT). Thus, there appears to be an important functional similarity between the effects produced by LI and EXT that parallels the methodo- 
logical symmetry inherent in the two procedures. The important implication of this finding is that the two phenomena may depend on a common process.

One possibility is that both LI and EXT involve retrieval processes (Bouton, 1991; Kraemer \& Roberts, 1984; Miller et al., 1986; Spear, 1981). Kraemer and Roberts offered a retrieval processing analysis that can be extended to the LI and EXT effects obtained here. The general idea is that animals independently code as separate memories the conditioning episode and the nonreinforced stimulus exposure, regardless of whether the latter occurs before or after conditioning. The contents of these two memories will overlap to the extent that the events themselves consist of similar features. In the case of taste aversion learning, the most relevant features will be those that define the flavor experiences. These features include attributes of the flavors (sweetness, intensity, palatability, viscosity, temperature, etc.), contextual cues (test environment, motivational status, handling cues, etc.) and event consequences (the aversiveness of a CTA episode, or the absence of aversiveness in the case of nonreinforced flavor exposure). The greater the similarity of the two memories, especially with respect to the stimulus features they represent, the greater the likelihood that test cues will activate, inappropriately, the memory for nonreinforced stimulus exposure. As a consequence, responding would be consistent with the event characteristics of nonreinforced flavor exposure-consumption of a palatable liquid-rather than the reaction consistent with the content of the memory for the conditioning episodeavoidance of the test flavor. This would explain the behavioral tendencies indicative of LI and EXT.

What remains to be explained is why generalized, but not primary, LI dissipates with delayed testing, and why spontaneous recovery appears with generalized, but not primary, EXT. The critical assumptions are that the retrievability of the memory for a nonreinforced stimulus episode declines more rapidly than that for a reinforced episode and that attributes of similar memories competitively interact with retrieval cues to determine which memory will be retrieved. With respect to the first assumption, Kraemer (1984) found that forgetting of a discrimination by pigeons was greater in terms of responding to the nonrewarded alternative $(S-)$ than to the rewarded alternative $(\mathbf{S}+)$, whether the forgetting was induced by proactive interference or merely a long retention interval. Data reported by Thomas (1981) with pigeons and by Serwatka and Spear (1988) with developing rats are consistent with these results. Also consistent is the apparently more rapid forgetting of conditioned inhibition than of conditioned excitation (Hendersen, 1978; Kraemer, 1984; Thomas, 1979). The basic assumption of better retention of reinforced than of nonreinforced experiences also has served previously with some success as a central theoretical premise (Staddon, 1974). The loss of the LI and EXT effects over time follows directly from the occurrence of more rapid forgetting of nonrewarded events than of rewarded events.
Another possibility is that there is a change in the relative retrievability of conflicting memories, but opposite in direction to that proposed by Kraemer and Roberts (1984). Perhaps the memory for conditioning increases in retrievability, whereas the memory for preexposure remains unchanged. Although there has been no direct test of the competing hypotheses, there is reason to favor the notion that the preexposure memory becomes less retrievable, rather than the idea that the conditioning memory becomes more retrievable. That generalized preexposure effects disappear when an interval is interpolated between preexposure and conditioning, as well as when testing is delayed, indicates that the preexposure memory is ephemeral relative to the conditioning memory (e.g., Kraemer \& Roberts, 1984).

A change in retrievability is not all that matters. The similarity between the test cues and the target attributes within a memory is also expected to influence the probability that a given memory will be retrieved. Retrievability can be thought of as a hypothetical threshold of activation that must be achieved in order for a memory to be retrieved. It is assumed that levels of activation initiated by a particular set of retrieval cues varies according to the similarity between those cues and the relevant features represented within each memory. The better the match between test cues and memorial content, the higher will be the resultant level of activation provided by those cues. For example, a memory representing attributes of maple flavor will be more strongly activated by a test presentation of maple than will a memory whose attributes include saccharin and not maple, although the latter may be activated by the maple flavor if its more general features (e.g., novel flavor) are similar to those of saccharin. As the retrievability of the memory declines-that is, as the activation threshold increases-higher levels of activation will be required in order to retrieve that memory. At some point, the threshold may be sufficiently high so that maple, with its limited activation potential, can no longer retrieve the saccharin memory, even though the memory associated with maple may still be retrieved by presentation of maple itself. Thus, the similarity between conflicting memories will combine with retention interval to produce the kinds of effects noted in the two experiments reported here.

There is more to recommend the retrieval interpretation of LI and EXT than merely the way in which these two phenomena are influenced by retention interval. For example, the results of Kasprow et al. (1984) indicate that some postacquisition experiences can mitigate the effects of CS preexposure, and the effects of similar postacquisition experiences similarly alter the consequences of EXT (e.g., "reinstatement" effect; Rescorla \& Heth, 1975). In addition, Baker and Mercier (1982) have summarized a body of evidence that challenges associative explanations of LI that depend on the notion of context conditioning; such explanations had diverged from interpretations of EXT. Equally impressive is the body of evidence and theoretical analysis presented by Bouton and his col- 
leagues (e.g., Bouton, 1991) that argues strongly for a retrieval failure interpretation of EXT. There is also a growing appreciation for the context specificity of $\mathrm{LI}$ (Hall \& Channell, 1986; Hall \& Honey, 1989; Hall \& Minor, 1984; Lovibond, Preston, \& Mackintosh, 1984; Lubow, Schnur, \& Rifkin, 1976), which in many ways parallels the context specificity found with EXT (Bouton, 1991).

The evidence on context specificity, retention interval effects, and reminder treatments with both LI and EXT presents substantial difficulties for acquisition-based interpretations of the effects of nonreinforced stimulus exposure, but the evidence is consistent with the proposition that LI and EXT involve the same retrieval mechanisms. Whether a retrievability approach to LI and EXT can accommodate other effects that may empirically distinguish the two phenomena remains to be seen.

\section{REFERENCES}

Baker, A. G., \& Mercier, P. (1982). Prior experience with the conditioning events: Evidence for a rich cognitive representation. In M. L. Commons, R. J. Herrnstein, \& A. R. Wagner (Eds.), Quantitative analysis of behavior: Acquisition (Vol. 3, pp. 117-143). New York: . Harper \& Row.

BEST, M. R., \& BARKER, L. M. (1977). The nature of "learned safety" and its role in the delay of reinforcement gradient. In L. M. Barker, M. R. Best, \& M. Domjan (Eds.), Learning mechanisms in food selection (pp. 295-315). Waco, TX: Baylor University Press.

BEst, M. R., \& GemBerLING, G. A. (1977). Role of short-term processes in the conditioned stimulus preexposure effect and the delay of reinforcement gradient in long-delay taste aversion learning. Journal of Experimental Psychology: Animal Behavior Processes, 3, 243-263.

Bouton, M. E. (1991). Context and retrieval in extinction and in other examples of interference in simple associative learning. In $\mathrm{L}$. W. Dachowski \& C. F. Flaherty (Eds.), Current topics in animal learning: Brain, emotion and cognition (pp. 25-53). Hillsdale, NJ: Erlbaum.

DOMJAN, M. (1983). Biological constraints on instrumental and classical conditioning: Implications for general process theory. In G. H. Bower (Ed.), The psychology of learning and motivation (Vol. 17, pp. 215-276). New York: Academic Press.

Grossberg, S. (1982). Processing of expected and unexpected events during conditioning and attention: A psychophysiological theory. Psychological Review, 89, 529-572.

Hall, G., \& Channell, S. (1986). Context specificity of latent inhibition in taste aversion learning. Quarterly Journal of Experimental Psychology, 36B, 121-139.

HaLL, G., \& HoNeY, R. C. (1989). Contextual effects in conditioning, latent inhibition and habituation: Associative and retrieval functions of contextual cues. Journal of Experimental Psychology: Animal Behavior Processes, 15, 232-241.

HALL, G., \& MrNoR, H. (1984). A search for context-stimulus associations in latent inhibition. Quarterly Joumal of Experimental Psychology, 36B, 145-169.

Hendersen, R. W. (1978). Forgetting of conditioned fear inhibition. Learning \& Motivation, 9, 16-30.

Holyoak, K. J., KoH, K., Nisbett, R. E. (1989). A theory of conditioning: Inductive learning within rule-based default hierarchies. Psychological Review, 96, 315-340.

KALAT, J. W. (1977). Stanus of "learned safety" or "learned noncorrelation" as a mechanism in taste aversion learning. In L. M. Barker, M. R. Best, \& M. Domjan (Eds.), Leaming mechanisms in food selection (pp. 273-293). Waco, TX: Baylor University Press.

Kalat, J. W., \& Rozin, P. (1973). "Learned safety" as a mechanism in long-delay taste aversion learning in rats. Journal of Comparative \& Physiological Psychology, 83, 198-207.

Kasprow, W. J., Catterson, D., Schachtman, T. R., \& Miller,
R. R. (1984). Attenuation of latent inhibition by postacquisition reminder. Quarterly Joumal of Experimental Psychology, 36B, 53-63.

KRAEMER, P. J. (1984). Forgetting of visual discriminations. Joumal of Experimental Psychology: Animal Behavior Processes, 10, 530-542.

Kraemer, P. J., HoffmanN, H., \& SPear, N. E. (1988). Attenuation of the CS-preexposure effect after a retention interval in preweanling rats. Animal Learning \& Behavior, 16, 185-190.

Kraemer, P. J., \& OssenkopP, K. P. (1986). The effects of flavor preexposure and test interval on conditioned taste aversions in rats. Bulletin of the Psychonomic Society, 24, 219-221.

Kraemer, P. J., Randall, C. K., \& Carbary, T. J. (1991). Release from latent inhibition with delayed testing. Animal Learning \& Behavior, 19, 139-145.

Kraemer, P. J., \& Roberts, W. A. (1984). The influence of flavor preexposure and test interval on conditioned taste aversions in the rat. Learning \& Motivation, 15, 259-278.

Lovibond, P. F., Preston, G. C., Mackintosh, N. J. (1984). Context specificity of conditioning, extinction, and latent inhibition. Joumal of Experimental Psychology: Animal Behavior Processes, 10, 360-375.

LuBow, R. E. (1973). Latent inhibition. Psychological Review, 79, 398-407.

Luвоw, R. E. (1989). Latent inhibition and conditioned attention theory. New York: Cambridge University Press.

Lubow, R. E., SchnuR, P., RifkIN, B. (1976). Latent inhibition and conditioned attention theory. Journal of Experimental Psychology: Animal Behavior Processes, 2, 163-174.

LuBOw, R. E., WeINER, I., \& SchNuR, P. (1981). Conditioned attention theory. In G. H. Bower (Ed.), The psychology of learning and motivation (Vol. 15, pp. 1-49). New York: Academic Press.

MACkIntosh, N. J. (1975). A theory of attention: Variations in the associability of stimuli with reinforcement. Psychological Review, 82, 276-298.

MaCKInTOSH, N. J. (1983). Conditioning and associative leaming. New York: Oxford University Press.

Miller, R. R., Kasprow, W. J., Schachtman, T. R. (1986). Retrieval variability: Sources and consequences. American Joumal of Psychology, 99, 145-218.

PAvLOV, I. P. (1927). Conditioned reflexes. London: Oxford University Press.

PeArCe, J. M. (1987). A model for stimulus generalization in Pavlovian conditioning. Psychological Review, 94, 61-73.

Pearce, J. M., \& Hall, G. (1980). A model for Pavlovian learning: Variations in the effectiveness of conditioned but not of unconditioned stimuli. Psychological Review, 87, 532-552.

Rescorla, R. A., HETH, C. D. (1975). Reinstatement of fear to an extinguished conditioned stimulus. Journal of Experimental Psychology: Animal Behavior Processes, 1, 88-96.

Rescorla, R. A., \& Wagner, A. R. (1972). A theory of Pavlovian conditioning: Variations in the effectiveness of reinforcement and nonreinforcement. In A. H. Black \& W. F. Prokasy (Eds.), Classical conditioning II: Current research and theory (pp. 64-99). New York: Appleton-Century-Crofts.

SerWATKa, J., \& SPEAR, N. E. (1988). Acquisition and retention of separate elements of a conditioned olfactory discrimination in preweanling rats. Developmental Psychobiology, 21, 145-159.

SPEAR, N. E. (1981). Extending the domain of memory retrieval. In N. E. Spear \& R. R. Miller (Eds.), Information processing in animals: Memory mechanisms (pp. 341-378). Hillsdale, NJ: Erlbaum.

SPEAR, N. E., \& SitZNER, J. H. (1967). Effect of initial nonrewarded trials: Factors responsible for increased resistance to extinction. Joumal of Experimental Psychology, 74, 525-537.

StAdDon, J. E. R. (1974). Temporal control, attention and memory. Psychological Review, 81, 375-391.

Strohen, K., BAKNer, L., Nordeen, M., \& Riccio, D. C. (1990, May). Post-conditioning recovery from the latent inhibition effect in conditioned taste aversion. Paper presented at the meeting of the Midwestern Psychological Association, Chicago, IL.

Tномаs, D. A. (1979). Retention of conditioned inhibition in a barpress suppression paradigm. Learning \& Motivation, 10, 161-177. Tномаs, D. R. (1981). Studies of long-term memory in the pigeon. 
In N. E. Spear \& R. R. Miller (Eds.), Information processing in animals: Memory mechanisms (pp. 257-290). Hillsdale, NJ: Erlbaum. WAGNER, A. R. (1978). Expectancies and the priming of STM. In S. H. Hulse, H. Fowler, \& W. K. Honig (Eds.), Cognitive processes in animal behavior (pp. 177-209). Hillsdale, NJ: Erlbaum.

WAGNER, A. R. (1981). SOP: A model of automatic memory process- ing in animal behavior. In N. E. Spear \& R. R. Miller (Eds.), Information processing in animals: Memory mechanisms (pp. 5-47). Hillsdale, NJ: Erlbaum.

(Manuscript received July 25, 1990 ; revision accepted for publication August 1, 1991.) 